\title{
In Vitro Evaluation of the Antifungal Activity of Ghassoul-Based Formulations with Oregano and Thyme Essential Oils against Penicillium sp.
}

\author{
Hamid Ziyat $\mathbb{D}^{1},{ }^{1}$ Mohammed Naciri Bennani, ${ }^{1}$ Safae Allaoui, ${ }^{1}$ Jamal Houssaini, \\ Hasna Nait M’barek $\mathbb{D}^{2},{ }^{2}$ Soukaina Arif $\mathbb{D}^{2}{ }^{2}$ and Hassan Hajjaj ${ }^{2}$ \\ ${ }^{1}$ Laboratory of Chemistry-Biology Applied to the Environment, \\ Research Team "Applied Materials and Catalyses" Chemistry Department, Faculty of Sciences, Moulay-Ismail University, \\ BP. 11201 Zitoune, Meknes, Morocco \\ ${ }^{2}$ Laboratory of Plant Biotechnology and Molecular Biology, Applied Mycology Team, Faculty of Sciences, \\ Moulay-Ismail University, BP. 11201 Zitoune, Meknes, Morocco \\ Correspondence should be addressed to Hamid Ziyat; ziyat.hamid@gmail.com
}

Received 12 November 2020; Revised 17 December 2020; Accepted 4 January 2021; Published 16 January 2021

Academic Editor: Davut Avci

Copyright (c) 2021 Hamid Ziyat et al. This is an open access article distributed under the Creative Commons Attribution License, which permits unrestricted use, distribution, and reproduction in any medium, provided the original work is properly cited.

\begin{abstract}
The essential oils from aromatic plants are today considered a suitable tool to protect stored grains from fungal attacks. The purpose of this work is to study the effect of formulations of thyme and oregano essential oil (EO) adsorbed on purified (Gh-P) and sulfuric acid-activated (Gh-A) ghassoul on the biological activity of fungal pathogens. Purified and activated ghassoul were characterized by XRD and FTIR, and EOs used in this study were issued from two medicinal plants known in Morocco and commercially available. Their chemical compositions were analyzed by the GC-MS technique. The main constituents of thyme EO were thymol (67.13\%), $\rho$-cymene (4.85\%), Z-caryophyllene (1.77\%), and $\gamma$-terpinene $(2.74 \%)$. Oregano EO contained carvacrol (59.82\%), $\gamma$-terpinene (10.85\%), and $\alpha$-pinene $(9.89 \%)$. This work focused on the study of the antifungal activity of EOs mixed with purified and sulfuric acid-activated ghassoul, in order to look for new natural bioactive products and assess their antifungal activity. Penicillium sp. was used as a pathogen agent for biological activity on Czapek agar medium. The results showed that the active ghassoul formulations had significant antifungal activity against Penicillium sp. Gh-A-thyme, Gh-A-thymol, and Gh-Aoregano had an inhibitory potential of more than $75 \%$ and excelled to retain it over time even after five months. On the other hand, the three purified ghassoul formulations (Gh-P-thyme, Gh-P-thymol, and Gh-P-oregano) showed an initial inhibitory power of less than $22 \%$, which was decreasing over time.
\end{abstract}

\section{Introduction}

Essential oils (EOs) are natural volatile oils, responsible for many odors produced by plants. These oils can be easily obtained using various extraction techniques, such as solvent extraction or distillation [1]. They are usually composed of single molecules, based on repetitive units of isoprene, called terpenes. Numerous uses of EOs have been studied, and they are highly appreciated in perfumery and cosmetics, as well as in food conservation and the pharmaceutical industry [2]. The most widely studied properties of EOs are their effects on microorganisms. They have been shown to inhibit growth and, in some cases, kill a wide range of bacteria, fungi, and parasites [1,3-14]. Other studies have been conducted on EOs as an alternative agent to control the growth of food-borne fungi [15].

Cosmetics and perfumery manufacturers started to integrate EOs more into their formulations. The substitution of a synthetic product with an EO increases the added value and does not harm the environment [16]. Moreover, Hossain et al. have enlarged the study of EOs formulations for storing cereals such as rice [10]. However, the industrial use of EOs has to face many problems because of their cost, the variability of their composition, their instability at storage 
since they are very volatile which poses a conservation problem, and also the allergenic potential of some of their constituents. Currently, it is recognized that temperature, light, and oxygen availability have a major impact on the preservation of EO integrity [17]. Besides, some of the constituents of EOs are allergens and therefore have to face restrictions of use. EOs are aromatic compounds, characterized by their high volatility and complex composition [18].

Some techniques reduce the effect of these problems which affect the industrial use of EOs. Two commonly used techniques are encapsulation and adsorption onto a substrate such as clay or the so-called formulation. They are used to immobilize the most volatile compounds in EO, stabilize it, protect it from light and temperature, and modulate its release by extending its kinetic profile. Also, to reduce costs for the industrial sector, the encapsulation of expensive active ingredients such as EOs makes it possible to reduce the concentrations introduced without affecting the efficiency of the finished product and the same thing for adsorption. The use of a clay powder flavored with EO has a double advantage due to the combined effects of clay and EO. Similar studies have been carried out for the adsorption of EOs on clay for insecticide applications, especially on corn weevil [19-21]. In the same sense, studies were done by Hossian et al. and prepared formulations based on EOs and nanocomposite to test the antifungal activities in vitro and in situ against Aspergillus niger, Aspergillus flavus, Aspergillus parasiticus, and Penicillium chrysogenum affecting rice [10].

The objective of this work is to regulate the volatilization of terpene compounds of EOs in order to increase their activity duration. To do this, the formulations were in the first stage prepared with different materials using the adsorption technique which makes it possible to immobilize EOs. The adsorption is made on purified ghassoul support and sulfuric acid-activated one. The EO of thyme as well as for its majority component thymol and the EO of oregano was used for this purpose. Then, the antifungal activity of the prepared formulations was studied and compared.

\section{Experimental}

2.1. Materials. The clay used in this study was a commercial ghassoul. It corresponds to the natural product without any treatment and dried at $100^{\circ} \mathrm{C}$ to remove the weakly bound water, then crushed, and sifted. Only aggregates with a diameter of less than $63 \mu \mathrm{m}$ were selected. Thymol of purity $>99 \%$, was supplied by Sigma-Aldrich. $\mathrm{NaCl}$ and $\mathrm{H}_{2} \mathrm{SO}_{4}$ were purchased from Aldrich, hexane $\left(\mathrm{C}_{6} \mathrm{H}_{14}\right)$ of purity $>85 \%$ and thymol of purity $>99 \%$ were, respectively, supplied by Loba Chemie and Sigma-Aldrich. The EOs used in this study, oregano and thyme, are commercial oils.

2.2. The Fungal Strain. The antifungal activity of the different formulations was evaluated on a Penicillium $s p$. strain, provided by the mycology laboratory of the biology department at Moulay Ismail University (Morocco). It was chosen because of the high frequency of contamination of food products and their involvement in human and animal pathology. This food-borne fungus was mainly isolated from cereals in the region of Meknes city in Morocco [22].

2.3. Instrumentation. The materials obtained were characterized by physicochemical techniques (XRD and FTIR).

The X-ray diffraction analyses were carried out on powder using a Philips PW 1800 device (copper $\mathrm{k} \alpha$ $\lambda=1.5418 \AA, 40 \mathrm{kV}, 20 \mathrm{~mA}$ ), available in our laboratory. The spectra of the different samples were recorded in a $2 \theta$ range of $5^{\circ}-70^{\circ}$, with an angular increment of $0.04^{\circ}$.

Infrared spectra were obtained using a fourier transform spectrometer (FTIR) of type JASCO 4000, equipped with a detector (TGS) and a ceramic source, separated by an optical system using a Michelson interferometer. The samples were packed in $12 \mathrm{~mm}$ diameter pellets. The absorption spectra were recorded in the range of 400 and $4000 \mathrm{~cm}^{-1}$ in absorbance or transmittance, with a resolution of $2 \mathrm{~cm}^{-1}$.

For identification of EO components, GC-MS THERMO Scientific type equipped with a capillary column HP-5 $(30 \mathrm{~m} \times 0.25 \mathrm{~mm})$ with a film thickness of $0.25 \mu \mathrm{m}$ was used. Identification of the constituents was based on a comparison of the retention times and computer matching against Wiley Data library. GC-MS chromatograms were scanned in the EO data library.

\subsection{Methods}

2.4.1. Purification of Ghassoul. Ghassoul, previously crushed and sieved to a size of less than $63 \mu \mathrm{m}$, was suspended in a solution of $\mathrm{NaCl}$ to replace all exchangeable cations $\left(\mathrm{Ca}^{2+}\right.$, $\mathrm{Mg}^{2+}, \mathrm{K}^{+}$, etc.) of the natural clay by $\mathrm{Na}^{+}$ions. For this purpose, a mass $m$ of clay was introduced into a beaker containing $100 \mathrm{ml}$ of $\mathrm{NaCl}$ solution $(1 \mathrm{M})$. After 4 hours of agitation, the clay particles were separated from the aqueous phase by centrifugation at a speed of $3400 \mathrm{rpm}$ for $10 \mathrm{~min}$. After 4 successive treatments (saturation-centrifugation). The suspension was subsequently centrifuged and washed several times with distilled water until the chloride ions were completely removed and the silver nitrate test was negative. The resulting suspension was dried at $70^{\circ} \mathrm{C}$ overnight, and the purified compound (Gh-P) was crushed with a porcelain mortar [23].

2.4.2. Preparation of Activated Ghassoul (Gh-A). The method used for acid activation of clays is that of Babaki et al. [24]. In a $500 \mathrm{ml}$ flask, $25 \mathrm{~g}$ of clay (particle size less than $63 \mu \mathrm{m})$ and $150 \mathrm{ml}$ of sulfuric acid solution ( $2 \mathrm{M}$ ) were introduced. The mixture is homogenized at a temperature of $90^{\circ} \mathrm{C}$ for $4 \mathrm{~h}$. After this period, the mixture was filtered on filter paper, and then the base was washed with distilled water until a $\mathrm{pH}$ around 7 was obtained. The activated clay obtained is then dried in the oven at $70^{\circ} \mathrm{C}$. The resulting clay was crushed with a porcelain mortar and stored in closed glass drumsticks. 
2.4.3. Preparation of the Formulation: Ghassoul/EO. The objective is to prepare a powdery formulation based on thymol, thyme EO, oregano EO, and purified ghassoul (Gh$\mathrm{P})$ or acid-activated ghassoul (Gh-A). To prepare these formulations, a mass of clay powder was transferred in a $100 \mathrm{~mL}$ flask, and the appropriate quantity of thyme EO, diluted in $10 \mathrm{~mL}$ of hexane, was added with the ratio [25]:

$$
\frac{m_{\mathrm{EO}}}{m_{\text {clay }}}=0.1
$$

with $m_{\mathrm{EO}}$ : mass of essential oil and $m_{\text {clay }}$ : mass of clay.

After mixing for about 3 hours, the mixture is placed in a water bath at $30^{\circ} \mathrm{C}$ until complete evaporation of the solvent. In the end, a thyme EO-flavored powder was obtained. The formulation was left in the open air for one month, then 3 months, and finally 5 months, and antifungal tests were carried out each time to evaluate the stability of the formulation; by the same method was prepared the formulation of Oregano EO and thymol.

\subsubsection{Antifungal Activity of Materials}

(1) Culture Medium. We used Czapek agar, a suitable and commonly used medium, for growing fungi. Per 1 liter of distilled water: $2 \mathrm{~g}$ of $\mathrm{NaNO}_{3} ; 1 \mathrm{~g}$ of $\mathrm{K}_{2} \mathrm{HPO}_{4} ; 0.5 \mathrm{~g}$ of $\mathrm{MgSO}_{4} * 7 \mathrm{H}_{2} \mathrm{O} ; 0.5 \mathrm{~g}$ of KCl; $0.01 \mathrm{~g}$ of $\mathrm{FeSO}_{4} * 7 \mathrm{H}_{2} \mathrm{O} ; 30 \mathrm{~g}$ of sucrose; $20 \mathrm{~g}$ of agar.

(2) Antifungal Tests. In $20 \mathrm{ml}$ of the Czapek Agar culture medium, $0.06 \mathrm{~g}$ of each formulation was aseptically added, then the mixture was poured into $90 \mathrm{~mm}$ diameter Petri dishes, and each box was seeded using a micropipette at the surface of the substrate. The fungus inoculum was prepared in the form of a spore suspension in distilled sterile water. A suspension volume was deposited in the center of the Petri dish, and each Petri dish was sealed with a parafilm. Finally, incubation was carried out at room temperature for 15 days. The incubation temperature was monitored to be $25^{\circ} \mathrm{C}$. Each test was repeated three times in order to minimize experimental error. Colony diameters were monitored over time to assess the inhibitory capacity of each formulation. The inhibitory capacity of the formulations on the fungal strain was calculated using the following formula [26]:

$$
\% \text { inhibitory power }=\frac{\text { control diameter }- \text { sample diameter }}{\text { control diameter }} * 100 .
$$

\section{Results and Discussion}

\subsection{Characterization of Materials}

3.1.1. XRD Analysis. According to the XRD patterns of the purified ghassoul presented in Figure 1, one reveals the presence of the characteristic lines of stevensite $(S)$ towards $2 \theta=5.91^{\circ}, 19.60^{\circ}, 37.29^{\circ}$, and $60.07^{\circ}$, and it is the majority phase of ghassoul. The presence of the dolomite phase $(D)$ was also clearly observed by the lines at $2 \theta=30.76^{\circ}$ and $41.11^{\circ}$. The quartz phase $(Q)$ in small quantity as an impurity appears with the lines at $2 \theta=21.05^{\circ}, 26.61^{\circ}$, and $51.15^{\circ}$ $[23,27,28]$.

The activation of ghassoul by sulfuric acid causes a decrease in the intensity of a few lines. This occurs mainly for stevensite and quartz, which means a reduction in its content. The decrease in intensity and the disappearance of some lines indicate that the crystallinity of ghassoul is greatly affected by the acidic activation, and the crystalline structure of ghassoul decomposes. It is also noted that the intensity of the dolomite phase decreases, which is due to the decomposition of carbonates by sulfuric acid. Subsequently, the activation process which is accompanied by the appearance of new fine and intense peaks suggests the reorganization of the ghassoul phases in the new structure, as shown in Figure 1. Similar results have already been described in literature $[29,30]$. In addition, the X-ray results of the activated ghassoul show that there is a change in the position of a few peaks (for example, $2 \theta=37.29^{\circ}$ at $36.66^{\circ}$ and $2 \theta=30.93^{\circ}$ at $29.17^{\circ}$ ), which is related to the change in distance between the layers. This is an indication of the dissolution of tetrahedral and octahedral leaves and the subsequent release of structural cations, that is, these cations were removed from octahedral positions, leaving some gaps [30].

3.1.2. FTIR Analysis. Figure 2 shows the FTIR spectra of the two clays. From spectra FTIR, the absorption bands which appear in the region 3400 to $3500 \mathrm{~cm}^{-1}$ correspond to the vibrations of the structural hydroxyl groups characteristic of ghassoul and to the elongation vibrations of the $\mathrm{OH}$ group of the adsorbed water. The exact position of these bands and their intensities vary according to the nature of the bonds of the molecules. They manifest themselves in purified ghassoul at $3441 \mathrm{~cm}^{-1}$ and for activated ghassoul at $3493 \mathrm{~cm}^{-1}$. These bands are preceded by two bands which appear as shoulders at 3668 and $3625 \mathrm{~cm}^{-1}$ for Gh-P and 3604 and $3551 \mathrm{~cm}^{-1}$ for Gh-A, which correspond to the stretching vibrations of structural hydroxyl of the $\mathrm{M}-\mathrm{OH}$ group $(M=\mathrm{Al}, \mathrm{Fe}, \mathrm{Mg})$ [31]. We note that, for activated ghassoul, these bands move towards low frequencies, which suggests an increase in the binding strength of $\mathrm{M}-\mathrm{OH}$ groups after treatment of the clay with $\mathrm{H}_{2} \mathrm{SO}_{4}$. The deformation vibration of $\mathrm{H}-\mathrm{OH}$ water molecules appears at $1627 \mathrm{~cm}^{-1}$ and $1619 \mathrm{~cm}^{-1}$ for Gh-P and Gh-A, respectively. While characteristic bands of carbonates were detected at $1442 \mathrm{~cm}^{-1}$ and $879 \mathrm{~cm}^{-1}$ for Gh-P and $1382 \mathrm{~cm}^{-1}$ and $960 \mathrm{~cm}^{-1}$ for Gh-A. These last bands decrease significantly in intensity after treatment by $\mathrm{H}_{2} \mathrm{SO}_{4}$, showing elimination of carbonates and therefore disappearance of the dolomite phase as was observed by XRD (Figure 1). The characteristic bands of the deformation vibrations of the Si$O$ bond of quartz are manifested at $672 \mathrm{~cm}^{-1}$ and $464 \mathrm{~cm}^{-1}$, for the purified ghassoul and its counterpart activated by sulfuric acid at $607 \mathrm{~cm}^{-1}$ and $472 \mathrm{~cm}^{-1}$. The infrared spectra of these solids also show the bands corresponding to the $\mathrm{Si}$ - 


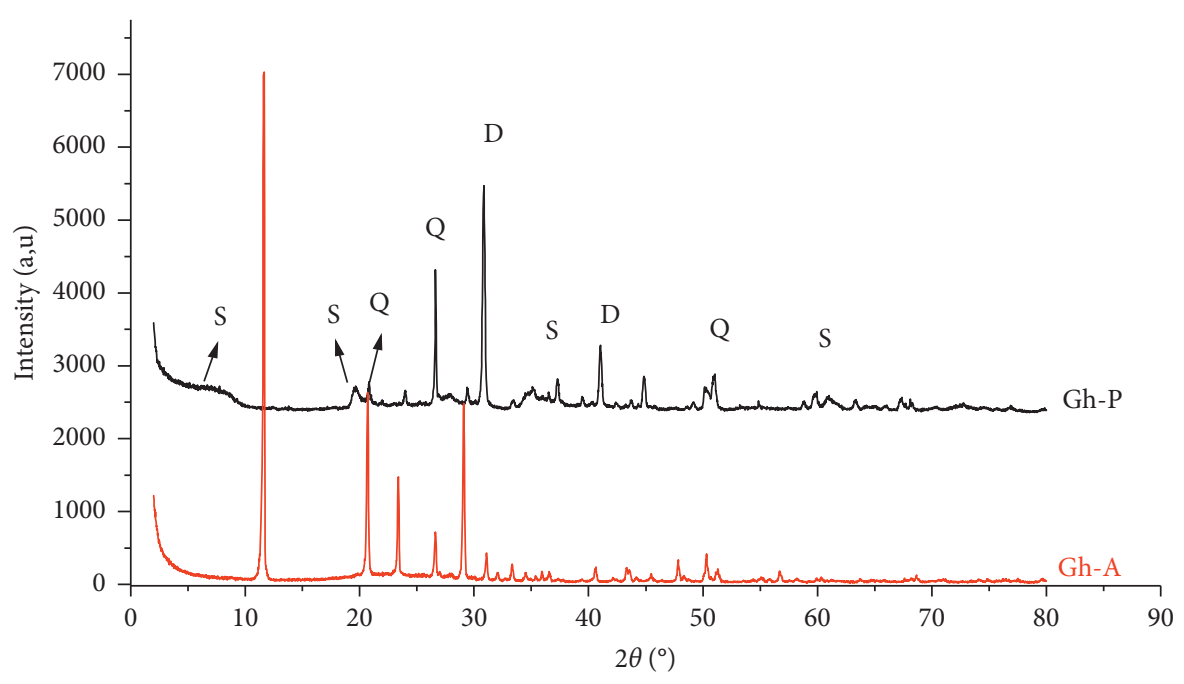

FIgURE 1: XRD patterns of Gh-P and Gh-A.

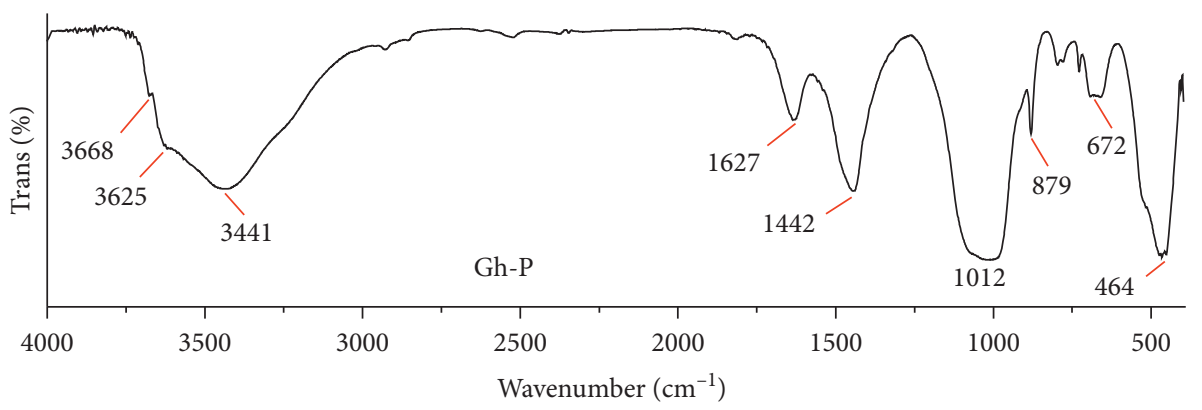

(a)

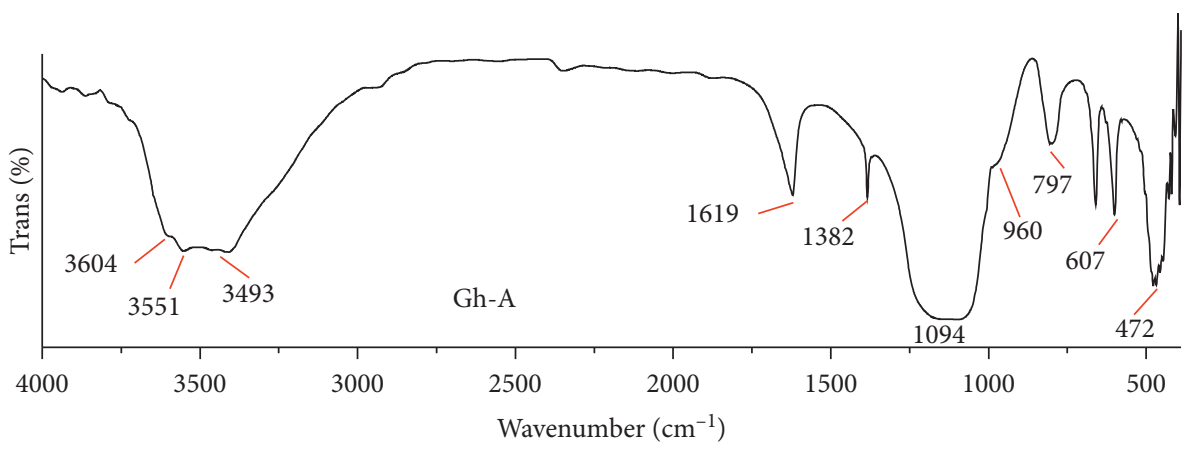

(b)

Figure 2: FTIR spectra of Gh-P (a) and Gh-A (b).

O-Si group elongation vibration of quartz towards $1017 \mathrm{~cm}^{-1}$ for the two purified and activated clays.

3.2. Chemical Composition of EOs. The EOs were analyzed by gas chromatography coupled with mass spectrometry (GC/ MS) to identify their main chemical components. The results obtained are presented in Tables 1 and 2 .

Thyme EO is composed mainly of thymol (67.13\%). In addition to this constituent, there are $\rho$-cymene $(4.85 \%)$, Z-caryophyllene $(1.77 \%)$, and $\gamma$-terpinene $(2.74 \%)$. Similar results were found by R. Ismaili et al. for the EO of Thymus vulgaris which consists mainly of thymol (42\%), $\rho$-cymene (23.7\%), and $\gamma$-terpinene (15.5\%) [32]. On the other hand, the EO of oregano is composed mainly of carvacrol (59.82\%), $\gamma$-terpinene $(10.85 \%)$, and $\alpha$-pinene (9.89\%), which account for about three-quarters of the total chemical composition accompanied by other constituents with relatively low contents. Similar results were found by RostroAlanis et al. for oregano EO whose majority compound is carvacrol with a higher concentration of $60.03 \%$ [33]. There is a slight difference in the chemical composition of the main components of the two EOs with those of literature studies, and this may be due to abiotic factors such as the specific 
TABle 1: Chemical composition of commercial thyme EO.

\begin{tabular}{lcccccc}
\hline $\mathrm{N}^{\circ}$ & Compound & Formula & Molar mass & RT & KI & Percentage \\
\hline 1 & $\alpha$-Pinene & $\mathrm{C}_{10} \mathrm{H}_{16}$ & 136 & 9.71 & 939 & 0.68 \\
2 & $\rho$-Cymene & $\mathrm{C}_{10} \mathrm{H}_{16}$ & 134 & 10.61 & 1024 & $\mathbf{4 . 8 5}$ \\
3 & -Terpinene & $\mathrm{C}_{10} \mathrm{H}_{16}$ & 136 & 11.98 & 1059 & 2.74 \\
4 & Terpinen-4-ol & $\mathrm{C}_{10} \mathrm{H}_{18} \mathrm{O}$ & 154 & 15.89 & 1177 & 1.07 \\
5 & Thymol & $\mathrm{C}_{10} \mathrm{H}_{14} \mathrm{O}$ & 150 & 20.74 & 1290 & $\mathbf{6 7 . 1 3}$ \\
6 & Carvacrol & $\mathrm{C}_{10} \mathrm{H}_{14} \mathrm{O}$ & 150 & 20.93 & 1299 & 0.12 \\
7 & Eugnol & $\mathrm{C}_{10} \mathrm{H}_{12} \mathrm{O}_{2}$ & 164 & 21.82 & 1359 & 0.80 \\
8 & Z-caryophyllene & $\mathrm{C}_{15} \mathrm{H}_{24}$ & 204 & 26.26 & 1408 & 1.77 \\
9 & $\beta$-Bisabolene & $\mathrm{C}_{15} \mathrm{H}_{24}$ & 204 & 27.12 & 1505 & 0.78 \\
10 & Trans-cadina-1(6); 4-diene & $\mathrm{C}_{15} \mathrm{H}_{24}$ & 204 & 27.42 & 1476 & 0.65 \\
11 & Caryophyllene oxide & $\mathrm{C}_{15} \mathrm{H}_{24} \mathrm{O}$ & 220 & 28.76 & 1583 \\
\hline
\end{tabular}

The bold values are the majority compounds of this essential oil.

TABLE 2: Chemical composition of commercial oregano EO.

\begin{tabular}{lcccccc}
\hline $\mathrm{N}^{\circ}$ & Compound & Formula & Molar mass & RT & KI & Percentage \\
\hline 1 & $\alpha$-Pinene & $\mathrm{C}_{10} \mathrm{H}_{16}$ & 136 & 9.72 & 939 & $\mathbf{9 . 8 9}$ \\
2 & $\alpha$-Terpinene & $\mathrm{C}_{10} \mathrm{H}_{16}$ & 136 & 10.48 & 1017 & 0.19 \\
3 & O-cymene & $\mathrm{C}_{10} \mathrm{H}_{14}$ & 134 & 10.63 & 1026 & $\mathbf{6 . 6 0}$ \\
4 & $\mathrm{C}_{10} \mathrm{H}_{16}$ & 136 & 12.03 & 1059 & 1096 \\
5 & $\gamma$-Terpinene & $\mathrm{C}_{10} \mathrm{H}_{18} \mathrm{O}$ & 154 & 13.40 & 10.85 \\
6 & Linalool & $\mathrm{C}_{10} \mathrm{H}_{18} \mathrm{O}$ & 154 & 15.90 & 1177 & 1.56 \\
7 & Terpinene-4-ol & $\mathrm{C}_{10} \mathrm{H}_{18} \mathrm{O}$ & 154 & 16.36 & 0.75 \\
8 & $\alpha$-Terpineol & $\mathrm{C}_{11} \mathrm{H}_{16} \mathrm{O}$ & 164 & 18.30 & 1244 & 0.24 \\
9 & Carvacrol, methyl ether & $\mathrm{C}_{10} \mathrm{H}_{15} \mathrm{O}$ & 150 & 20.16 & 1290 \\
10 & Thymol & $\mathrm{C}_{10} \mathrm{H}_{14} \mathrm{O}$ & 150 & 20.74 & 1299 & 4.05 \\
11 & Carvacrol & $\mathrm{C}_{15} \mathrm{H}_{24}$ & 204 & 24.28 & 1408 & $\mathbf{5 9 . 8 2}$ \\
12 & Z-caryophyllene & $\mathrm{C}_{15} \mathrm{H}_{24}$ & 204 & 27.42 & 1476 & 2.94 \\
13 & Trans-cadina-1(6); 4-diene & $\mathrm{C}_{15} \mathrm{H}_{24} \mathrm{O}$ & 220 & 28.76 & 1583 & 0.52 \\
\hline
\end{tabular}

The bold values are the majority compounds of this essential oil.

climate of the origin regions of the samples. Effectively, geographic factors such as altitude, soil type, and harvest season can affect the chemical composition.

3.3. Antifungal Activity of Formulations. The antifungal activity results of the prepared thymol, thyme, and oregano formulations are summarized in Table 3.

The results obtained in this study (Table 3 and Figure 3 ) show that, after one month, all formulations have maximum inhibitory power except $\mathrm{Gh}$-A-oregano which has a potency of $86.25 \pm 4.31 \%$. While after three months, this power remains maximum for Gh-A-thymol and decreased for all formulations, with a remarkable decrease for Gh-P-thyme from $100 \pm 5 \%$ to $52.94 \pm 2.64 \%$. However, after 5 months the inhibitory power reaches minimum values of $22.66 \pm 1.13 \%$, $18.33 \%$, and $19.04 \pm 0.95 \%$ for the formulations Gh-P-oregano, Gh-P-thyme, and Gh-P-thymol, respectively.

The other compounds showed significant inhibition on the growth of the fungus. The formulations Gh-A-oregano, Gh-A-thyme, and Gh-A-thymol showed the highest activity compared to the other formulations after 5 months, as shown in Table 3, Gh-A-thyme has a significant fungicidal activity of $93 \pm 4.66 \%$, Gh-A-oregano has an inhibitory potency of $80 \pm 4 \%$, and Gh-A-thymol has $76.19 \pm 3.80 \%$. It can be seen that the antifungal activity of Gh-A-thyme
TABLE 3: The antifungal activity of the prepared formulations of thymol, thyme, and oregano.

\begin{tabular}{lccc}
\hline \multirow{2}{*}{ Formulation } & \multicolumn{3}{c}{ Power of inhibition (\%) } \\
& After 1 month & After 3 months & After 5 months \\
\hline Gh-P-oregano & $100 \pm 5$ & $93.90 \pm 4.69$ & $22.66 \pm 1.13$ \\
Gh-P-thyme & $100 \pm 5$ & $52.94 \pm 2.64$ & $18.33 \pm 0.91$ \\
Gh-P-thymol & $100 \pm 5$ & $72 \pm 3.6$ & $19.04 \pm 0.95$ \\
Gh-A- & $86.25 \pm 4.31$ & $84.14 \pm 4.2$ & $\mathbf{8 0} \pm \mathbf{4}$ \\
oregano & $100 \pm 5$ & $94.11 \pm 4.7$ & $\mathbf{9 3 . 3 3} \pm \mathbf{4 . 6 6}$ \\
Gh-A-thyme & $100 \pm 5$ & $100 \pm 5$ & $\mathbf{7 6 . 1 9} \pm \mathbf{3 . 8 0}$ \\
Gh-A-thymol &
\end{tabular}

The bold values represent formulations that provide the best inhibition results.

formulation $(93.33 \pm 4.66 \%)$ is higher than that of Gh-Athymol formulation $(76.19 \pm 3.80 \%)$, and this significant activity is related to the synergistic effect between the components of the EO $[34,35]$. Figure 4 shows the inhibition rate of some formulations used in this work.

This antifungal activity is related to the active substance: thymol, carvacrol, and the amount adsorbed by Gh-A. Similar results were found by Abbaszadeh et al. who found potent thymol inhibitory activity against fungi in the study of thymol antifungal activity, carvacrol, eugenol, and menthol to control the growth of food-borne fungi [15]. 


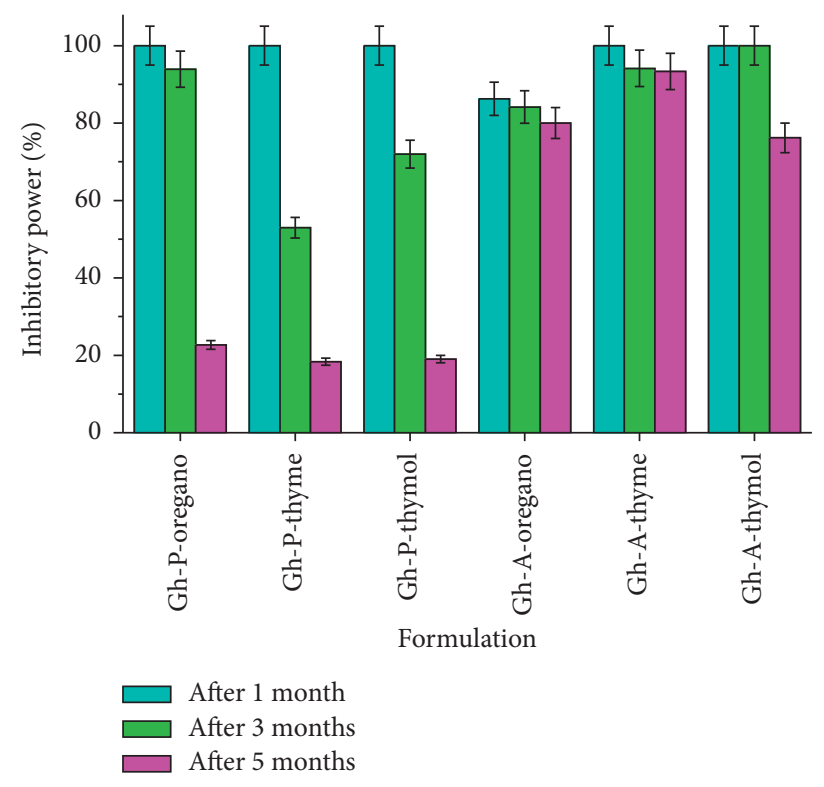

Figure 3: The inhibitory power of formulations.

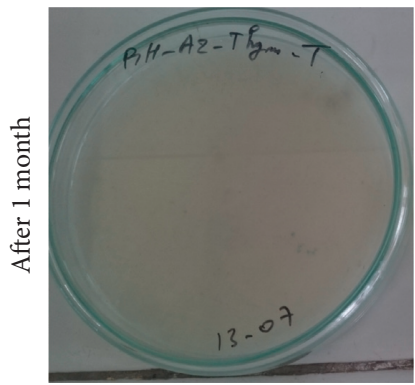

Gh-A-thyme

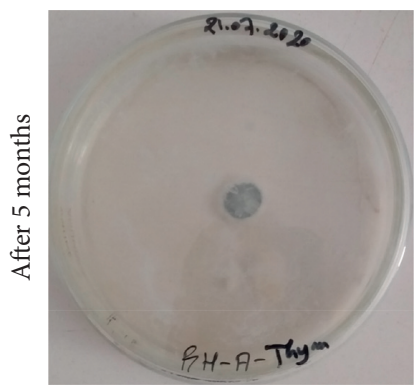

Gh-A-thyme

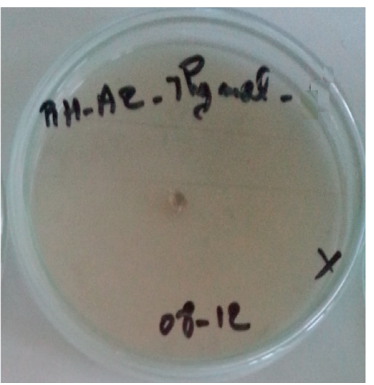

Gh-A-thymol

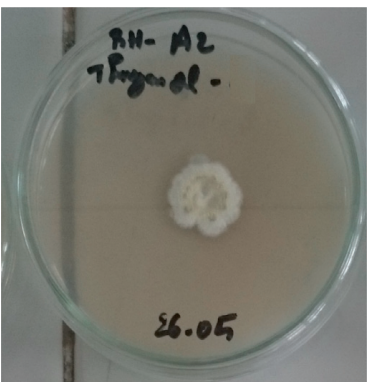

Gh-A-thymol

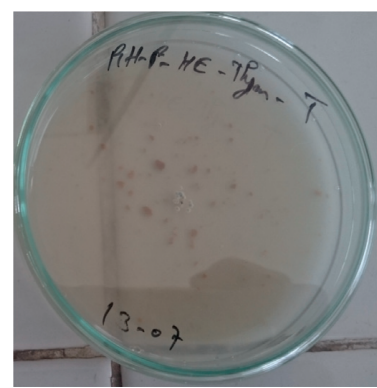

Gh-P-thyme

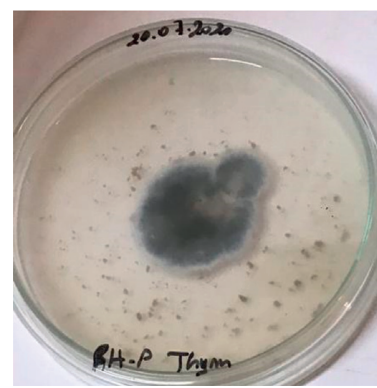

Gh-P-thyme

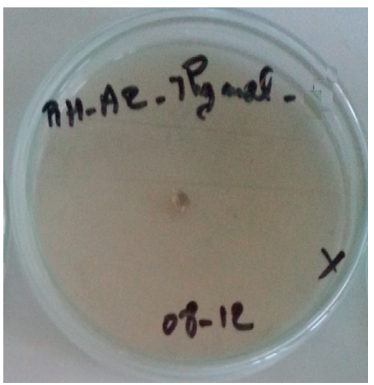

Gh-P-thymol

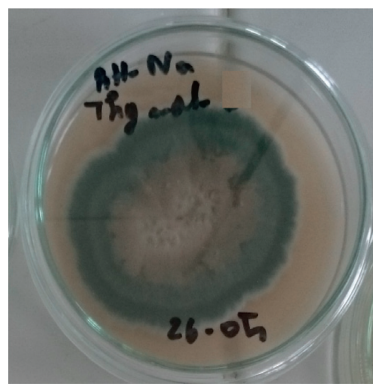

Gh-P-thymol

FIgURE 4: Inhibition rate of the prepared formulation against Penicillium, after 15 days incubation at $25^{\circ} \mathrm{C}$.

In another study, Bedoya-Serna et al. studied the antifungal activity of nanoemulsions encapsulating oregano (Origanum vulgare) EO: in vitro study and application in Minas Padrão cheese [12]. They reported that nanoemulsions encapsulating oregano essential oil had an inhibitory effect against Cladosporium, Fusarium, and Penicillium genera. Also, similar studies have been done by Hossain et al. and have shown that chitosan-based nanocomposite films loaded with EO mixtures of thyme-oregano, thyme-tea tree, and thyme-peppermint EO mixtures showed significant antifungal activity against Aspergillus niger,
Aspergillus flavus, Aspergillus parasiticus, and Penicillium chrysogenum, reducing their growth by $51-77 \%$ [10].

While the formulations based on Gh-P showed the lowest activity, this is due to the material of Gh-P which adsorbs less than Gh-A. During the activation process, a considerable amount of interfoliar cations was substituted by $\mathrm{H}^{+}$, which increases the specific surface $[24,36]$. These transformations in layers of clay result in significant changes in cationic exchange capacity (CEC) and chemical and mineralogical characteristics [37]. More than that, when Ghassoul is activated by sulfuric acid, the surface of the material becomes rich in hydrogenated 
protons, so these protons create hydrogenic interactions. This phenomenon favors the adsorption of the active ingredient of the EO on the clay. Based on these results, the formulation based on GH-A better retains the components of the EOs studied. Hence, this Gh-A-EO formulation is more stable than Gh-P-EO. This leads us to say that acid-activated clays have a much less negative surface charge than basic clays, and oxygenated terpene compounds would be subject to several types of interactions, both specific and nonspecific, namely, hydrogen bonds, on the one hand, and electrostatic and Van der Waals on the other, while hydrocarbon compounds would simply be limited to Van der Waals interactions.

\section{Conclusion}

The formulations of the two materials showed that, in in vitro, a significant antifungal activity against the tested fungus (Penicillium sp.) especially for the acid-activated ghassoul, according to the results, found that this material keeps its inhibitory power with time even after 5 months either for Gh-A-thyme or Gh-A-thymol or Gh-A-oregano which have an inhibition power higher than $75 \%$. On the other hand, for the material which is purified Ghassoul, its inhibiting power decreases with time for the three formulations, Gh-P-thyme or Gh-P-thymol or Gh-P-oregano, which have an inhibiting power less than $22 \%$. This great bioactive power observed in the tested formulations based on activated ghassoul is attributed to the active principle of the EOs tested, essentially thymol from thyme and carvacrol from oregano, and secondly to the quantity adsorbed by the active ghassoul which is greater than the quantity adsorbed by the purified ghassoul. Thus, the use of these plant-derived components with clays, in particular, the material Ghassoul which presents a capacity to retain the active principles for EOs, could be considered as an alternative to synthetic fungicides to inhibit fungal growth during grain storage.

\section{Nomenclature}

\section{EO:}

Gh-P:

Essential oil

Gh-A:

Purified ghassoul

Gh-A-thyme:

Activated ghassoul

Gh-A-thymol:

Gh-A-

oregano:

Gh-P-thyme:

Gh-P-thymol:

Gh-P-

oregano:

Gh-A-EO:

Formulation-activated ghassoul-thyme

Formulation-activated ghassoul-thymol

Formulation-activated ghassoul-oregano

Formulation-purified ghassoul-thyme

Formulation-purified ghassoul-thymol

Formulation-purified ghassoul-oregano

oil

Gh-P-EO: $\quad$ Formulation-purified ghassoul-essential oil.

\section{Data Availability}

All data underlying the findings of this study are fully available without restriction.

\section{Conflicts of Interest}

The authors declare that they have no conflicts of interest.

\section{Acknowledgments}

This work was done in the framework of the project (PPR2) supported by the Ministry of National Education, Professional Training, Higher Education and Scientific Research (MENFPESRS), Morocco, and National Center for Scientific and Technical Research (CNRST)/Rabat, Morocco.

\section{References}

[1] N. El-Mougy, "Effect of some essential oils for limiting early blight (Alternaria solani) development in potato field," Journal of Plant Protection Research, vol. 49, no. 1, pp. 57-62, 2009.

[2] Y. Li, A.-S. Fabiano-Tixier, and F. Chemat, "Essential oils: from conventional to green extraction," in Essential Oils as Reagents in Green Chemistry, pp. 9-21, Springer, Berlin, Germany, 2014.

[3] N. Robledo, P. Vera, L. López, M. Yazdani-Pedram, C. Tapia, and L. Abugoch, "Thymol nanoemulsions incorporated in quinoa protein/chitosan edible films; antifungal effect in cherry tomatoes," Food Chemistry, vol. 246, pp. 211-219, 2018.

[4] S. Inouye, N. Maruyama, H. Yamaguchi, and S. Abe, "A novel method to estimate the contribution of the vapor activity of essential oils in agar diffusion assay," Nippon Ishinkin Gakkai Zasshi, vol. 47, no. 2, pp. 91-98, 2006.

[5] Z. Schelz, J. Molnar, and J. Hohmann, "Antimicrobial and antiplasmid activities of essential oils," Fitoterapia, vol. 77, no. 4, pp. 279-285, 2006.

[6] A. Rosato, C. Vitali, N. De Laurentis, D. Armenise, and M. Antonietta Milillo, "Antibacterial effect of some essential oils administered alone or in combination with Norfloxacin," Phytomedicine, vol. 14, no. 11, pp. 727-732, 2007.

[7] M. V. Arasu, P. Viayaraghavan, S. Ilavenil, N. A. Al-Dhabi, and K. C. Choi, "Essential oil of four medicinal plants and protective properties in plum fruits against the spoilage bacteria and fungi," Industrial Crops and Products, vol. 133, pp. 54-62, 2019.

[8] A. Kunicka-Styczyńska, M. Sikora, and D. Kalemba, “Antimicrobial activity of lavender, tea tree and lemon oils in cosmetic preservative systems," Journal of Applied Microbiology, vol. 107, no. 6, pp. 1903-1911, 2009.

[9] K. A. Hammer, C. F. Carson, and T. V. Riley, "Antimicrobial activity of essential oils and other plant extracts," Journal of Applied Microbiology, vol. 86, no. 6, pp. 985-990, 1999.

[10] F. Hossain, P. Follett, S. Salmieri, K. D. Vu, C. Fraschini, and M. Lacroix, "Antifungal activities of combined treatments of irradiation and essential oils (EOs) encapsulated chitosan nanocomposite films in in vitro and in situ conditions," International Journal of Food Microbiology, vol. 295, pp. 33-40, 2019.

[11] F. Hu, X.-F. Tu, K. Thakur et al., "Comparison of antifungal activity of essential oils from different plants against three fungi," Food and Chemical Toxicology, vol. 134, Article ID 110821, 2019.

[12] C. M. Bedoya-Serna, G. C. Dacanal, A. M. Fernandes, and S. C. Pinho, "Antifungal activity of nanoemulsions encapsulating oregano (Origanum vulgare) essential oil: in vitro 
study and application in Minas Padrão cheese," Brazilian Journal of Microbiology, vol. 49, no. 4, pp. 929-935, 2018.

[13] K. Munhuweyi, O. J. Caleb, A. J. van Reenen, and U. L. Opara, "Physical and antifungal properties of $\beta$-cyclodextrin microcapsules and nanofibre films containing cinnamon and oregano essential oils," $L W T$, vol. 87, pp. 413-422, 2018.

[14] S. Acosta, A. Chiralt, P. Santamarina, J. Rosello, C. GonzálezMartínez, and M. Cháfer, "Antifungal films based on starchgelatin blend, containing essential oils," Food Hydrocolloids, vol. 61, pp. 233-240, 2016.

[15] S. Abbaszadeh, A. Sharifzadeh, H. Shokri, A. R. Khosravi, and A. Abbaszadeh, "Antifungal efficacy of thymol, carvacrol, eugenol and menthol as alternative agents to control the growth of food-relevant fungi," Journal de Mycologie Médicale, vol. 24, no. 2, p. e51, 2014.

[16] A. Kerdudo, "Optimisation de la conservation des cosmetiques: impact de la formulation, recherche de nouveaux conservateurs naturels, encapsulation," 2015.

[17] C. Turek and F. C. Stintzing, "Stability of essential oils: a review," Comprehensive Reviews in Food Science and Food Safety, vol. 12, no. 1, pp. 40-53, 2013.

[18] S. Burt, "Essential oils: their antibacterial properties and potential applications in foods-a review," International Journal of Food Microbiology, vol. 94, no. 3, pp. 223-253, 2004.

[19] M. M. G. Nguemtchouin, M. B. Ngassoum, L. S. T. Ngamo, X. Gaudu, and M. Cretin, "Insecticidal formulation based on Xylopia aethiopica essential oil and kaolinite clay for maize protection," Crop Protection, vol. 29, no. 9, pp. 985-991, 2010.

[20] M. M. G. Nguemtchouin, M. B. Ngassoum, L. S. T. Ngamo et al., "Adsorption of essential oil components of Xylopia aethiopica (Annonaceae) by kaolin from Wak, Adamawa province (Cameroon)," Applied Clay Science, vol. 44, no. 1-2, pp. 1-6, 2009.

[21] K. S. Moussa, V. Charles, S. J. Pierre, A. J. Thor, and A. Bélanger, "Efficacy of essential oil of Ocimum basilicum L. and O. gratissimum L. applied as an insecticidal fumigant and powder to control Callosobruchus maculatus (Fab.) [Coleoptera: bruchidae]," The Journal of Stored Products Research, vol. 37, no. 4, pp. 339-349, 2001.

[22] H. N. M’Barek, B. Taidi, T. Smaoui, M. Ben Aziz, A. Mansouri, and H. Hajjaj, "Isolation, screening and identification of ligno-cellulolytic fungi from northern central Morocco," Biotechnology, Agronomy, Society and Environment, vol. 23, no. 4, pp. 207-217, 2019.

[23] H. Ziyat, M. Naciri Bennani, H. Hajjaj et al., "Adsorption of thymol onto natural clays of Morocco: kinetic and isotherm studies," Journal of Chemistry, vol. 2020, Article ID 4926809, 10 pages, 2020.

[24] H. Babaki, A. Salem, and A. Jafarizad, "Kinetic model for the isothermal activation of bentonite by sulfuric acid," Materials Chemistry and Physics, vol. 108, no. 2-3, pp. 263-268, 2008.

[25] M. G. M. Nguemtchouin, M. B. Ngassoum, P. Chalier, R. Kamga, L. S. T. Ngamo, and M. Cretin, "Ocimum gratissimum essential oil and modified montmorillonite clay, a means of controlling insect pests in stored products," Journal of Stored Products Research, vol. 52, pp. 57-62, 2013.

[26] N. Ahmad, S. Sultana, G. Kumar, M. Zuhaib, S. Sabir, and M. Z. Khan, "Polyaniline based hybrid bionanocomposites with enhanced visible light photocatalytic activity and antifungal activity," Journal of Environmental Chemical Engineering, vol. 7, no. 1, Article ID 102804, 2019.

[27] M. Ajbary, A. Santos, V. Morales-Flórez, and L. Esquivias, "Removal of basic yellow cationic dye by an aqueous dispersion of Moroccan stevensite," Applied Clay Science, vol. 80-81, pp. 46-51, 2013.

[28] A. Benhammou, A. Yaacoubi, L. Nibou, and B. Tanouti, "Adsorption of metal ions onto Moroccan stevensite: kinetic and isotherm studies," Journal of Colloid and Interface Science, vol. 282, no. 2, pp. 320-326, 2005.

[29] J. P. Nguetnkam, R. Kamga, F. Villiéras, G. E. Ekodeck, A. Razafitianamaharavo, and J. Yvon, "Assessment of the surface areas of silica and clay in acid-leached clay materials using concepts of adsorption on heterogeneous surfaces," Journal of Colloid and Interface Science, vol. 289, no. 1, pp. 104-115, 2005.

[30] K. Al-Essa, "Activation of Jordanian bentonite by hydrochloric acid and its potential for olive mill wastewater enhanced treatment," Journal of Chemistry, vol. 2018, Article ID 8385692, 10 pages, 2018.

[31] N. I. A. Acevedo, M. C. G. Rocha, and L. C. Bertolino, "Mineralogical characterization of natural clays from Brazilian Southeast region for industrial applications," Cerâmica, vol. 63 , no. 366 , pp. 253-262, 2017.

[32] R. Ismaili, A. Lamiri, and K. Moustaid, "Etude de l'activité antifongique des huiles essentielles de trois plantes aromatiques marocaines (study of the antifungal activity of essential oils of three moroccan aromatic plants)," International Journal of Innovation Science and Research, vol. 12, no. 2, pp. 2351-8014, 2014.

[33] M. d. J. Rostro-Alanis, J. Báez-González, C. Torres-Alvarez, R. Parra-Saldívar, J. Rodriguez-Rodriguez, and S. Castillo, "Chemical composition and biological activities of oregano essential oil and its fractions obtained by vacuum distillation," Molecules, vol. 24, no. 10, p. 1904, 2019.

[34] A. E. Edris and E. S. Farrag, "Antifungal activity of peppermint and sweet basil essential oils and their major aroma constituents on some plant pathogenic fungi from the vapor phase," Nahrung/Food, vol. 47, no. 2, pp. 117-121, 2003.

[35] M. Lis-Balchin, S. G. Deans, and E. Eaglesham, "Relationship between bioactivity and chemical composition of commercial essential oils," Flavour and Fragrance Journal, vol. 13, no. 2, pp. 98-104, 1998.

[36] N. Yildiz and A. Çalimli, "Alteration of three Turkish bentonites by treatment with $\mathrm{Na}_{2} \mathrm{CO}_{3}$ and $\mathrm{H}_{2} \mathrm{SO}_{4}$," The Turkish Journal of Chemistry, vol. 26, no. 3, pp. 393-401, 2002.

[37] M. Önal, Y. Sarikaya, T. Alemdaroğlu, and I. Bozdoğan, "The effect of acid activation on some physicochemical properties of a bentonite," The Turkish Journal of Chemistry, vol. 26, no. 3, pp. 409-416, 2002. 